University of Massachusetts Amherst

From the SelectedWorks of Julian Tyson

1986

The Rapid Determination of Chemical Oxygen Demand in Waste Waters and Effluents by Flow Injection Analysis

Julian Tyson

J. M. H. Appleton

R. P. Mounce 


\title{
THE RAPID DETERMINATION OF CHEMICAL OXYGEN DEMAND IN WASTE WATERS AND EFFLUENTS BY FLOW INJECTION ANALYSIS
}

\author{
J. M. H. APPLETON and J. F. TYSON \\ Department of Chemistry, University of Technology, Loughborough, Leicestershire, \\ LE11 $3 T U$ (Great Britain)
}

R. P. MOUNCE

British Gas Corporation, London Research Station, Michael Road, London, SW6 2AD (Great Britain)

(Received 6th September 1985)

\section{SUMMARY}

Chemical oxygen demand (COD) and the limitations of the standard method of determination are discussed. A fully automated method based on a commercial flow injection analyzer is described. The results obtained with a processing time of $3 \mathrm{~min}$ are comparable with those given by the standard method for a wide range of types of effluent. Good agreement was achieved between the results for various standard materials. Mercury(II) is added to the sample to prevent chloride interference. Silver(I) catalyst can be incorporated into the reagent. A limitation to performance is caused by the maximum cycle time of $198 \mathrm{~s}$ of the analyzer.

The discharge of polluting organic matter to water-courses is strictly controlled by water authorities. When an ecological balance is maintained, natural waters are purified by biochemical oxidation by micro-organisms which utilize the polluting substances as sources of carbon whilst consuming dissolved oxygen for respiration. The rate of purification depends on many conditions, including the water temperature and the nature of the pollutants.

In Europe and the U.S.A., a widely-used index of waste water quality is chemical oxygen demand (COD) which relates to the oxygen required for complete oxidation of the sample. The COD is an arbitrary empirical measurement obtained by subjecting the sample to oxidation by chromic acid under prescribed conditions. Despite its importance, the manual method has several disadvantages. It is complicated and time-consuming, requiring toxic reagents; precision depends heavily on operator skill, and about $3 \mathrm{~h}$ is required to obtain a result. This delay presents holding and discharge problems for industries producing large volumes of effluents. As a result of these shortcomings, improvements or alternatives to the traditional COD method have been sought. The major considerations in this are the extent to which the traditional method is entrenched in industrial and analytical practice and in legislation, the extreme range of effluent types, and the fact that most 
effluents are complex mixtures of substances with varying susceptibilities to oxidation. Present and planned schedules dealing with effluent analysis require many COD determinations and considerable manpower commitment. The development of an automated method would improve the efficiency of pollution control and the operation of biofermentors and effluent treatment plants.

An AutoAnalyzer procedure for the determination of COD was described by Adelman [1] in 1966. More recently, extensive work on the determination of COD by flow injection analysis (f.i.a.) has been reported by Korenaga and Ikatsu who used permanganate [2] or dichromate [3] as the oxidant. The latter method gave about $75 \%$ of the result by the conventional method in $20 \mathrm{~min}$. However, labour-saving versions of the traditional apparatus remain widely used and there are continued research efforts in the same direction [4]. When an alternative method for COD is based on milder conditions than those employed in the standard method, more stable compounds in the samples may resist oxidation, leading to low results. The use of correction factors to derive standard COD values from such results is questionable, because those probably relate to the masses of readily-oxidizable material in the samples, which is not a simple measure of COD. Therefore, an alternative COD method is valid only if it achieves the same degree of oxidation of the sample as the standard method. Hence conditions and chemistry should correspond as closely as possible to those conventionally used.

In the standard procedure, the interference of chloride is reduced to acceptable levels by the addition of mercury(II) sulphate. The degree of suppression depends on the ratio of mercury(II) to chloride ions [5]. Dobbs and Williams [6] recommended a ratio of at least 5:1. Certain compounds, notably those containing an aromatic nucleus, may be only partly and irreproducibly oxidized. Heterocyclic compounds, such as pyridine, are particularly resistant to oxidation. Conventionally, silver sulphate (about $0.5 \%$ in the refluxing mixture) is added to catalyse the oxidation of straight-chain alcohols and acids. The oxidation of acetic acid, for example, is improved from about $2 \%$ to about $95 \%$ of the theoretical value by the use of silver sulphate [7]. Thus any procedure which omits mercury(II) and silver(I) ions cannot be expected to reproduce standard COD values for all samples.

Ideally, then, a method suitable for automated determination of COD should be quick, simple, cheap, and as effective as the standard method in oxidizing the samples. This paper describes an attempt to realize these objectives with conventional f.i.a. equipment. In the proposed method, a reagent stream, containing potassium dichromate and sulphuric acid, is merged with a distilled water carrier into which samples are injected. After the merging point, whilst the stream flows through a suitable reactor, the sample is oxidized and $\mathrm{Cr}(\mathrm{VI})$ species in the reagent are reduced to $\mathrm{Cr}$ (III). Downstream, the absorbance of chromate is monitored at $445 \mathrm{~nm}$. Reagent consumption is indicated by a transient negative departure from the steady-state absorbance. In this paper, response is shown as the magnitude $\Delta V$ (in $\mathrm{mV}$ ) of this negative peak. 


\section{EXPERIMENTAL}

\section{Reagents}

Analytical-grade chemicals and distilled water were used unless specified otherwise.

Potassium dichromate/sulphuric acid reagent. About $600 \mathrm{ml}$ of sulphuric acid, obtained from a newly opened 2.5 -l bottle, was placed in a beaker in a sink. A solution of $3.0 \mathrm{~g}$ of potassium dichromate in $25 \mathrm{ml}$ of distilled water was added dropwise down the inside of the beaker with vigorous stirring (addition of the acid to the solution precipitates chromium trioxide). After cooling, the contents of the beaker were returned to the bottle and mixed to yield approximately $2.5 \mathrm{l}$ of reagent.

Reference solutions for COD determinations. Solutions with a theoretical $800 \mathrm{mg}^{-1}$ COD were prepared containing potassium hydrogenphthalate $\left(0.680 \mathrm{~g} \mathrm{l}^{-1}\right)$, D-glucose $\left(0.750 \mathrm{~g} \mathrm{l}^{-1}\right)$, sodium oxalate $\left(6.70 \mathrm{~g} \mathrm{l}^{-1}\right)$, sodium salicylate $\left(0.571 \mathrm{~g} \mathrm{l}^{-1}\right)$ and sodium acetate $\left(1.025 \mathrm{~g} \mathrm{l}^{-1}\right)$.

A $1000 \mathrm{mg} \mathrm{l}^{-1}$ chloride solution was prepared from sodium chloride. The mercury(II) sulphate was Fisons SLR grade.

\section{Instrumentation}

A Tecator 5020 flow injection analyzer was used with a 5032 spectrophotometer (detector/controller/printer) equipped with a 5000-0428 Flowcell (volume $18 \mu \mathrm{l}, 10-\mathrm{mm}$ path length) and a 5007 autosampler. Some work involved the use of an external Gilson Minipuls 2 peristaltic pump. The peaks were recorded with a Tekman TE200 chart recorder. The manifold represented schematically in Fig. 1 is the final version resulting from considerable preliminary development and optimization, as described below.

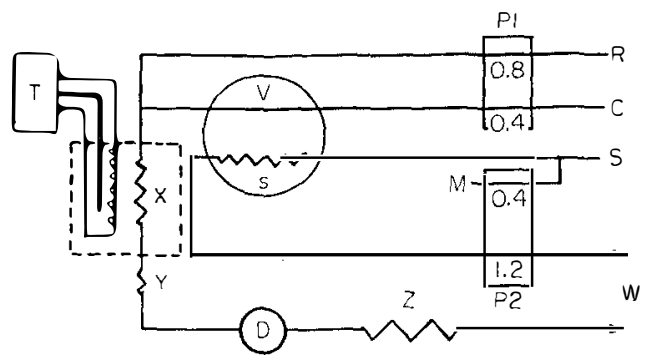

Fig. 1. Flow-injection manifold for the determination of COD. P1, an external Gilson Minipuls II peristaltic pump operated continuously on speed setting 700; P2, right-hand pump of the Tecator 5020 Analyzer; V, injection valve fitted with a sample loop of volume s; X, Y and $\mathrm{Z}$, coils of $0.58 \mathrm{~mm}$ i.d. teflon tubing (Anachem) of lengths 3.0, 0.75 and $1.5 \mathrm{~m}$, respectively. Reaction coil $\mathrm{X}$ is housed in an oven equipped with a temperature control $\mathrm{T} ; \mathrm{Y}$ is a water-cooled coil and $\mathrm{Z}$ a back-pressure coil. $\mathrm{R} ; \mathrm{C}, \mathrm{S}$ and $\mathbf{M}$ are streams of chromic acid reagent, water, sample and mercury(II) sulphate, respectively. $R$ is pumped via Acidflex tubing; the other pump tubes are Tygon. The figures indicate the flow rates quoted in $\mathrm{ml} \mathrm{min}^{-1}$ for the pump tubes used. The thumb wheel settings were $99 / 99 / 99 / 30 / 9 / 6$, the left-hand pump being switched off. 


\section{Procedures}

Development of apparatus. The first manifold was based on an appraisal of the chemistry involved, the instrumentation available and the experiences of earlier workers [1-3]. The major object was to obtain rapid and effective oxidation of the sample using simple apparatus. The effects of temperature, flow rates, reagent composition and manifold geometry were investigated. By varying parameters within the instrumental limitations, conditions giving acceptable sensitivity and calibration linearity were identified.

Determination of COD. Initially the performance of the method was investigated using solutions with equivalent theoretical COD's of various substances. Sodium acetate was included, in order to demonstrate the catalytic action of silver sulphate. Investigation of the suppression of chloride interference by mercury(II) sulphate necessitated incorporation of this substance into the test solutions because it is only sparingly soluble in the chromic acid reagent. The responses to injections of potassium hydrogenphthalate, with and without mercury(II) sulphate, were compared. Samples for analysis were industrial effluents supplied by the British Gas Corporation and trade effluents obtained locally. Their COD values, determined routinely by independent authorities using the standard method, were compared with the results obtained by the flow-injection method.

\section{RESULTS AND DISCUSSION}

\section{Development of apparatus}

The Tecator 5020 Analyzer has the advantages of a ready-made automated system with programmable pumping and built-in signal evaluation. It also has some limitations. The analytical cycle is limited to just over $3 \mathrm{~min}$ (198 s). As the standard method for COD involves refluxing for $2 \mathrm{~h}$, this limitation represents a considerable challenge. Initially, the coils $\mathrm{X}$ and $\mathrm{Y}$ (Fig. 1) were $5 \mathrm{~m}$ and $2 \mathrm{~m}$, respectively, and the injected volume of sample was $260 \mu \mathrm{l}$; the reaction coil X was immersed in an oil bath. This system performed well but required an analytical cycle time of about $7 \mathrm{~min}$, which could not be automated with the 5020 Analyzer.

As reported by Korenaga and Ikatsu [3] , pumping the reagent presents a problem. Some difficulty in maintaining baseline stability was experienced with the 5020 peristaltic pump when tubes of different bores and/or materials were fitted over a common pump wheel. Pumping efficiency is a function of the tension in the compression band. The optimum tension for one tube may be quite unsuitable for another. Also relative movement and wear of the tubes tend to alter the flow rates. Better results were obtained when the multichannel Gilson pump replaced pump P1 (Fig. 1) because this pump restricts lateral movement of the tubes on the rollers and allows independent optimization of the compression of each tube. Even so, the useful lifetime of the Acidflex pump tube was only $3-4 \mathrm{~h}$ of continuous operation.

The temperature of the heating bath must be constant, because it influ- 
ences the steady-state absorbance (increased temperature gives lower absorbance). An ordinary commercial thermostat, providing $160 \pm 8^{\circ} \mathrm{C}$, produced a sinusoidal baseline and was replaced by a purpose-built analogue controller which gave a thermal stability better than $\pm 1^{\circ} \mathrm{C}$ at $160^{\circ} \mathrm{C}$. In the first trials, conducted at $120^{\circ} \mathrm{C}$, bubbles formed in the stream and were removed by splitting the stream immediately before the flow cell. An inverted glass $Y$ junction was used; the stream entered by one arm and $20 \%$ flowed out to the detector via the other while the rest, together with the bubbles, flowed up the vertical stem to waste. As expected, the signal was very noisy.

However, from the outset it was intended to achieve reaction conditions in the manifold at least as aggressive as those used in the standard method. In order to achieve the required temperature $\left(160^{\circ} \mathrm{C}\right)$ in the stream without it boiling, the proportion of sulphuric acid was increased above that used conventionally. If carefully degassed distilled water was used as the carrier, for the preparation of standards and for the dilution of the concentrated samples, the reaction proceeded, even at a bath temperature of $200^{\circ} \mathrm{C}$, with no bubble formation. Baseline noise, caused largely by the formation of minute bubbles as the stream approached boiling point, was drastically reduced. The debubbling device was thus redundant. As a final development, the oil bath was replaced by a purpose-built oven.

\section{The optimization of response}

An attempt to reduce the analytical cycle time by increasing the carrier and reagent flow rates led to increased reagent consumption and higher manifold pressures, with reduced baseline stability and increased risk of reagent spillage. A cycle time compatible with the performance of the 5020 was therefore achieved by adjusting the flow rates and decreasing the manifold dimensions to those described in Fig. 1.

The variation of response with sample volume, carrier flow rate and reaction temperature is summarized in Figs. 2-4. The most powerful of these effects is changing the sample volume (s). Increasing this volume leads to increased sensitivity and reduced linear calibration range (Fig. 2). For fixed flows of reagent $(R)$, the carrier flow rate $(C)$ determines both the sampleto-reagent ratio and the initial length of the sample zone at the confluence point. Figure 3 illustrates results obtained by varying $C$ by means of an external Gilson peristaltic pump. Optimum sensitivity occurs around the 400 speed setting. Under the chosen operating conditions, baseline absorbance increased with heating bath temperature in a manner which suggested increasing thermal decomposition of the reagent (Fig. 4). However, stopping the flow for 1-2 min produced no further reagent depletion, so some other thermal change must be involved. Mere mixing of the reagent and carrier streams generates a stream temperature of about $100^{\circ} \mathrm{C}$, so the use of a lower bath temperature actually cools the mixture. The net peak response reaches a maximum at a bath temperature of about $180^{\circ} \mathrm{C}$. 


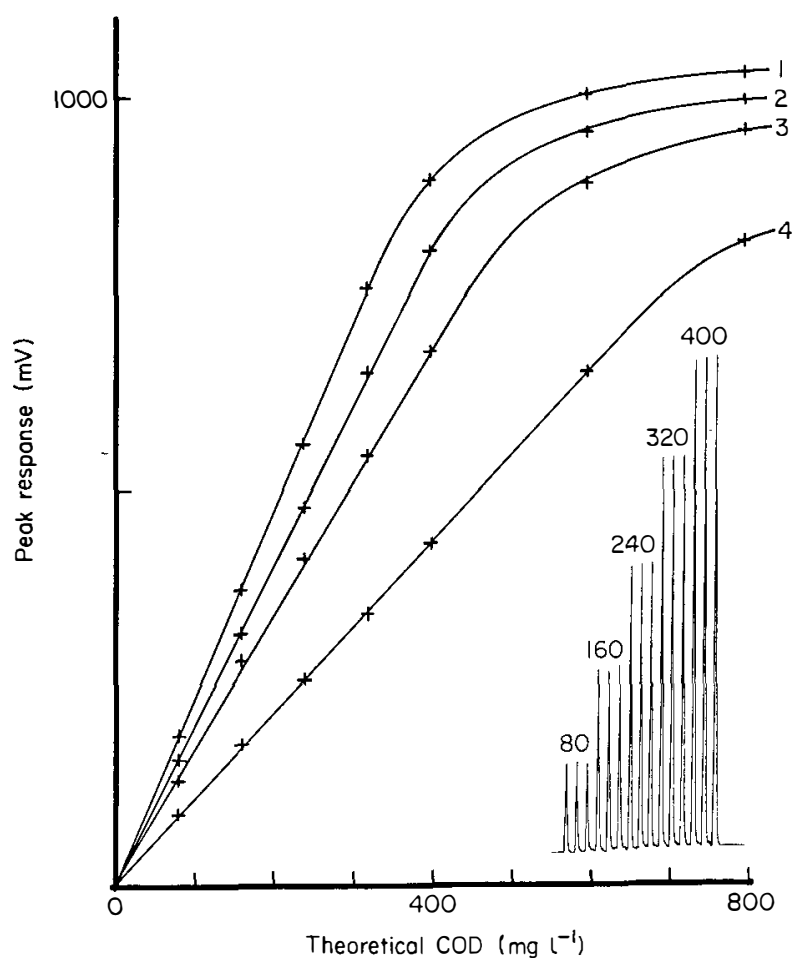

Fig. 2. The effect of sample volume on sensitivity and linear range of calibration. Curves: (1) $130 \mu \mathrm{l}$; (2) $110 \mu \mathrm{l}$; (3) $90 \mu \mathrm{l}$; (4) $60 \mu \mathrm{l}$. Conditions: potassium hydrogenphthalate as reference substance; $176^{\circ} \mathrm{C}$ oven; 18 cycles per hour. The inset shows the $90-\mu l$ peaks for $80,160,240,320,400 \mathrm{mg} \mathrm{l}^{-1}$ COD solutions.

\section{The determination of $C O D$}

Various pure substances were used as reference materials for COD. Even in the absence of silver sulphate catalyst, glucose, sodium salicylate, sodium oxalate and potassium hydrogenphthalate produced calibration plots that were identical within $4 \%$ (Table 1), which suggested that these substances were completely oxidized. In contrast, the peak responses produced by equivalent (COD) solutions of sodium acetate were scarcely distinguishable from the baseline noise (Fig. 5A). Incorporation of silver sulphate $\left(7.5 \mathrm{~g} \mathrm{l}^{-1}\right)$ into the reagent (i.e., $0.5 \%$ after merging with the carrier) produced a dramatic increase (to more than $90 \%$ of the theoretical value) in these responses. The responses of the industrial samples 3 and 4 were unchanged (Fig. 5B).

The masking of chloride interferences was investigated by using solutions of potassium hydrogenphthalate $\left(200 \mathrm{mg} \mathrm{l}^{-1} \mathrm{COD}\right)$, containing $5.0 \mathrm{~g} \mathrm{l}^{-1}$ of mercury(II) sulphate and chloride levels between 0 and $500 \mathrm{mg} \mathrm{l}^{-1}$ (Fig. 6). Introduction of the mercury salt by saturating the reagent with it, effective up to $50 \mathrm{mg} \mathrm{l}^{-1}$ chloride, would be suitable for the determination of the 

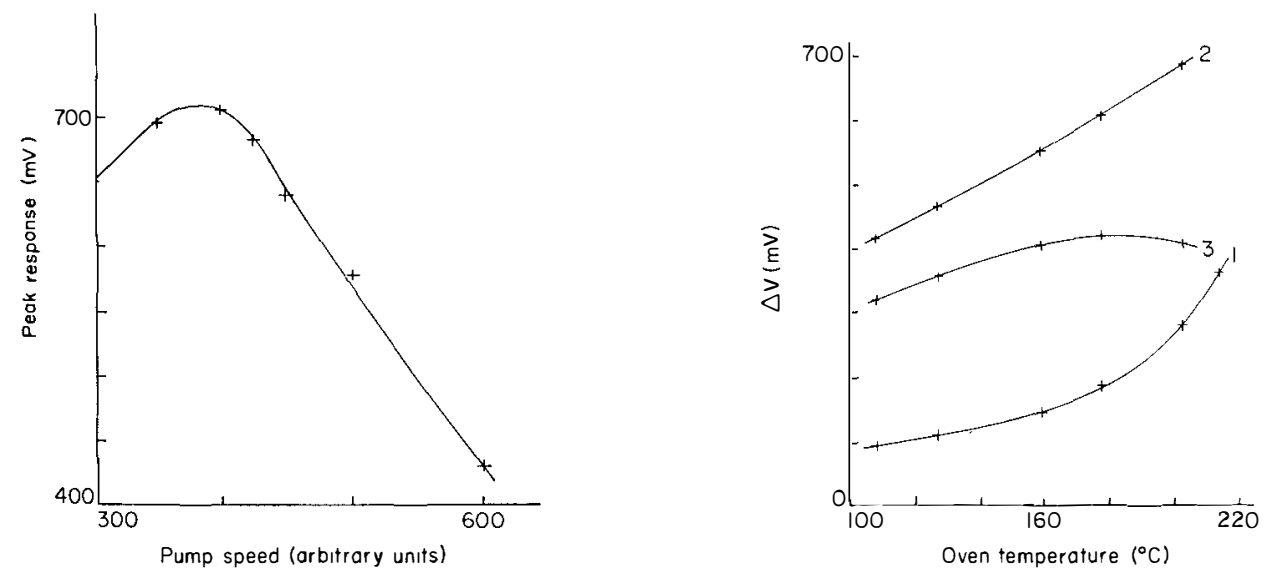

Fig. 3. The effect of increasing the carrier flow rate $(C)$ for a constant reagent flow. $C$ was pumped at various rates using the Gilson pump with $\mathrm{O} / \mathrm{W}$ coded tubing $\left(0.8 \mathrm{ml} \mathrm{min}^{-1}\right)$ whilst $R$ was pumped at a constant rate by the pump of the 5020 Analyzer using $B / B$ coded tubing $\left(1.2 \mathrm{ml} \mathrm{min}^{-1}\right)$. Potassium hydrogenphthalate solution (200 $\mathrm{mg} \mathrm{l}^{-1} \mathrm{COD}$ ) was injected $(160 \mu \mathrm{l})$; temperature was $160^{\circ} \mathrm{C}$.

Fig. 4. The effect of heating bath temperature on baseline and peak response. The baseline was initially set at $950 \mathrm{mV}$ at ambient temperature $\left(24^{\circ} \mathrm{C}\right)$. Curves 1 and 2 show the interval $\Delta V$ from this level to the baseline and peak, respectively, as temperature increases. Plot 3 shows the net interval $\Delta V$ between baseline and peak response. Potassium hydrogenphthalate solution ( $\left.240 \mathrm{mg} \mathrm{l}^{-1} \mathrm{COD}\right)$ was injected $(110 \mu \mathrm{l})$. Injection at a bath temperature of $214^{\circ} \mathrm{C}$ produced bubbles in the stream, which disrupted the output.

COD of river water, which usually contains about $10 \mathrm{mg} \mathrm{l}^{-1}$ chloride. The results demonstrate serious chloride interference in the determination of COD when no mercury(II) sulphate is added.

Reproducible performance of the apparatus was restricted chiefly by base-

TABLE 1

Peak responses $(\mathrm{mV})$ for different substances

\begin{tabular}{|c|c|c|c|c|c|c|c|c|}
\hline \multirow[t]{2}{*}{ Substance } & \multicolumn{5}{|c|}{ Theoretical COD $\left(\mathrm{mg} \mathrm{l}^{-1}\right)$} & \multicolumn{3}{|c|}{ Least-squares regression ${ }^{a}$} \\
\hline & 80 & 160 & 240 & 320 & 400 & Slope & Intercept & $r$ \\
\hline Glucose & 156 & 310 & 463 & 625 & 754 & 1.90 & 4.0 & 0.9996 \\
\hline Salicylate ${ }^{b}$ & 159 & 320 & 485 & 651 & 794 & 2.00 & 0.7 & 0.9998 \\
\hline Oxalate ${ }^{b}$ & 159 & 321 & 484 & 659 & 792 & 2.01 & 0.9 & 0.9996 \\
\hline KHPc & 153 & 313 & 482 & 654 & 806 & 2.04 & -6.0 & 0.9998 \\
\hline Mean & 157 & 316 & 478 & 647 & 784 & 1.983 & 0.4 & 0.9997 \\
\hline
\end{tabular}

${ }^{a}$ Origin included in data, because peaks are measured from baseline which corresponds to the blank; $r$ is Pearson's correlation coefficient. Sample volume $110 \mu \mathrm{l}$; reactor temperature $176^{\circ} \mathrm{C}$. ${ }^{b}$ As sodium salt. ${ }^{c}$ Potassium hydrogen phthalate. 

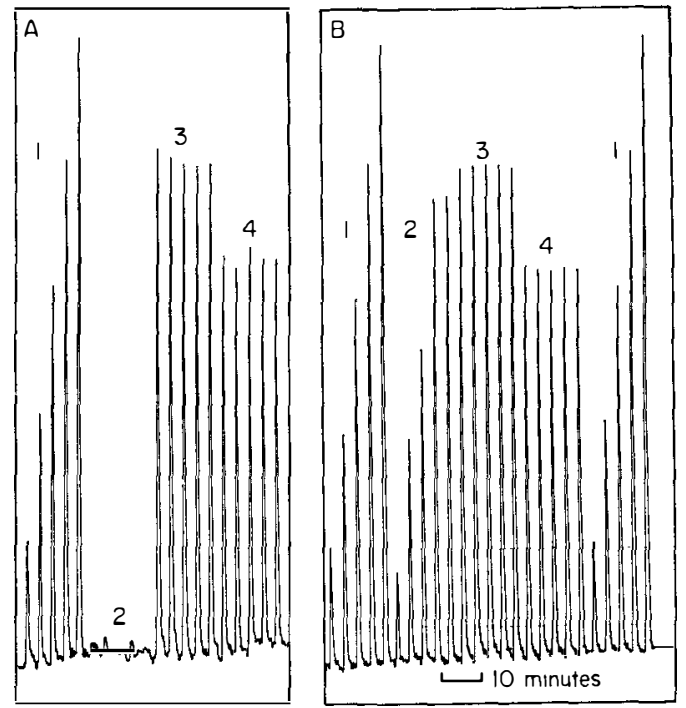

Fig. 5. The catalytic action of silver(I). A, No silver(I) added; B, $7.5 \mathrm{~g} \mathrm{l}^{-1}$ silver sulphate added to reagent. Peaks: (1) potassium hydrogenphthalate $\left(80,160,240,320,400 \mathrm{mg} \mathrm{l}^{-1}\right.$ COD); (2) sodium acetate solutions of the same theoretical COD values; (3) gas works effluent, diluted 100 -fold; (4) chemical factory effluent, diluted 20 -fold.

line instability. A relative standard deviation of about $0.65 \%$ was attainable for 20 injections of $240 \mathrm{mg} \mathrm{l}^{-1}$ COD potassium hydrogenphthalate solution when new pump tubes were fitted. The deviation increases to $2-3 \%$ as the tubes wear.

Although, with the present system, reaction time is severely limited, the determinations on real samples (Table 2) frequently produced COD values greater than $90 \%$ of those obtained by the standard method. In some cases,

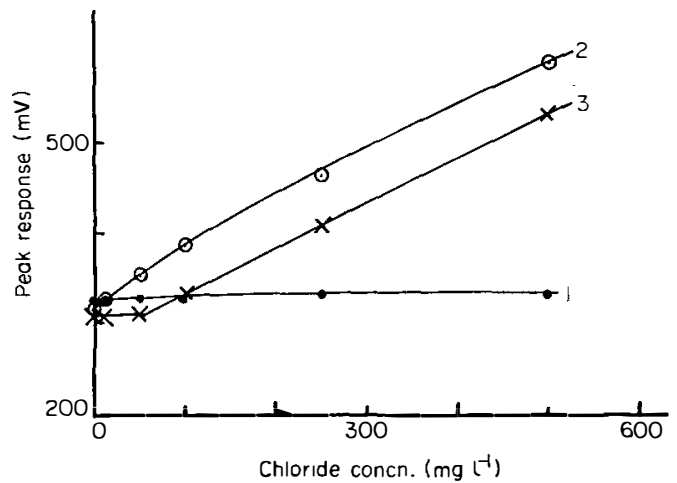

Fig. 6. The masking of chloride interference by mercury(II) sulphate in the measurement of $200 \mathrm{mg} \mathrm{l}^{-1} \mathrm{COD}$ (potassium hydrogenphthalate): (1) $5.0 \mathrm{~g} \mathrm{l}^{-1}$ mercury(II) sulphate added to sample; (2) no mercury(II) sulphate added; (3) reagent saturated with mercury(II) sulphate. Conditions: sample volume $110 \mu \mathrm{l} ; 160^{\circ} \mathrm{C}$. 
TABLE 2

Comparison of COD values $\left(\mathrm{mg}^{-1}\right)$ obtained by the standard and proposed methods

\begin{tabular}{|c|c|c|c|c|c|c|c|}
\hline \multirow[t]{2}{*}{ Sample } & \multirow[t]{2}{*}{ Sample type } & \multicolumn{2}{|c|}{ COD found } & \multirow[t]{2}{*}{ Sample } & \multirow[t]{2}{*}{ Sample type } & \multicolumn{2}{|l|}{ COD found } \\
\hline & & Standarda & F.i.a.b & & & Standarda & F.i.a.b \\
\hline 1 & Dye waste & 672 & 560 & 12 & Brewery waste & 1621 & 1555 \\
\hline 2 & Dye waste & 1591 & 1400 & 13 & Chemical manufacture & 2055 & 2052 \\
\hline 3 & Dye waste & 296 & 268 & 14 & Fabric washing & 2372 & 2057 \\
\hline 4 & Dye waste & 435 & 413 & 15 & Circuit board & 899 & 890 \\
\hline 5 & Dye waste & 467 & 443 & & manufacture & & \\
\hline 6 & Brewery waste & 2006 & 1818 & 16 & Chemical manufacture & 5070 & 5000 \\
\hline 7 & Cattle market & 2530 & 2528 & 17 & Gas-works effluent & 22000 & 23300 \\
\hline & waste & & & 18 & Gas-w orks ef fluent & 28000 & 27900 \\
\hline 8 & Dye waste & 1571 & 1379 & 19 & Gas-works effluent & 31000 & 28500 \\
\hline 9 & Dye waste & 356 & 302 & 20 & Gas-works effluent & 34000 & 31000 \\
\hline 10 & Dye waste & 399 & 270 & 21 & Gas-works effluent & 37000 & 32000 \\
\hline 11 & Dye waste & 597 & 584 & & & & \\
\hline
\end{tabular}

a Values determined by the standard method by Severn-Trent Water Authority, Wanlip (Samples 1-15), Fison's Scientific Equipment, Loughborough (Sample 16) and British Gas Corporation, Fulham (Samples 17-21). b With silver sulphate ( $7.5 \mathrm{~g} \mathrm{l}^{-1}$ ) added to the reagent.

the agreement is quite good, but overall accuracy would be further improved by the use of longer reaction times. Nevertheless, these results compare favourably with those of Korenaga and Ikatsu [3].

\section{Conclusions}

The results of this feasibility study indicate that the determination of COD is possible with conventional equipment for f.i.a. without the need for an expensive high-pressure system and a 50-m manifold [3]. A significantly higher degree of sample oxidation has been achieved by raising the temperature. The reaction proceeds without the formation of bubbles, and without excessive decomposition of the reagent, owing to the brief exposure and the absence of local overheating. Silver sulphate is incorporated into the reagent when necessary, or when there is doubt. The interference of chloride ions is prevented by merging the sample with mercury(II) sulphate solution before injection into the manifold.

In order to obtain the best agreement with results obtained by the standard method, certain restrictions imposed by the apparatus used here need to be relaxed. The 5020 Analyzer restricts the analytical cycle to $198 \mathrm{~s}(2 \times$ $99 \mathrm{~s})$, which limits the sample residence time in the reaction coil to about $2 \mathrm{~min}$. This is inadequate for the complete oxidation of many samples, even when the more aggressive reagent and elevated temperature are used. More time would permit the use of a longer manifold, slower flow and larger sample volumes, giving better reproducibility of results, as revealed during preliminary work with a 7-m manifold and manual injection of samples.

Peristaltic pumps are unsuitable for pumping the viscous chromic acid reagent. Pump tubes become quickly fatigued, leading to excessive baseline 
drift and variation in the carrier/reagent ratio. The method requires a fixed displacement pump capable of operating at 30-40 psi. The study again emphasizes the great value and versatility of f.i.a. in analytical chemistry. Over the last 10 years the technique has been used with imagination and ingenuity to improve the performance and efficiency of countless analyses. Slow reactions were a major challenge. Stopped flow is one answer. This paper has presented the more traditional solution of increasing the concentration and temperature of the reacting species.

The authors express their sincere thanks to Mr. A. F. Bower (Electronics Engineer, Department of Chemistry, LUT) who designed the oven and thermistor-controlled analogue power supply; and to Messrs. P. Child (Fisons Scientific Equipment, Loughborough), P. Kirkwood (British Gas Corporation, London Research Station), R. Yates and G. Boorman (Severn Trent Water Authority) for kindly providing analysed effluent samples. Financial support for J. M. H. A. by the British Gas Corporation is gratefully acknowledged.

\section{REFERENCES}

1 M. H. Adelman, Automation in Analytical Chemistry, Vol. 1, Technicon Symposia 1966, Mediad, New York, 1967.

2 T. Korenaga and H. Ikatsu, Analyst (London), 106 (1981) 653.

3 T. Korenaga and H. Ikatsu, Anal. Chim. Acta, 141 (1982) 201.

4 S. J. Edwards and M. Allen, Analyst (London), 109 (1984) 671.

5 Department of the Environment Standing Committee of Analysts, Chemical Oxygen Demand (Dichromate Value) of Polluted and Waste Waters, H.M.S.O., London, 1977.

6 R. A. Dobbs and R. T. Williams, Anal. Chem., 35 (1963) 1064.

7 W. A. Moore, F. J. Ludzack and C. C. Ruchhoft, Anal. Chem., 23 (1951) 1297. 